\title{
Efeitos da Lei do Piso nos vencimentos de professores do Piauí e do Rio Grande do Norte no contexto da política de fundos
}

\author{
The effects of the Base Salary Law on municipal teachers from Piauí and Rio \\ Grande do Norte remuneration in funds policy contexts \\ Efectos de la Ley de Piso en los sueldos de los profesores de Piauí y de Rio \\ Grande del Norte en el contexto de la política de fondos
}

LUIS CARLOS SALES

MAGNA FRANÇA

\begin{abstract}
Resumo: Este artigo analisa os efeitos da Lei do Piso nos vencimentos de professores das redes públicas municipais de Teresina e de Natal e das redes estaduais do Piauí (PI) e do Rio Grande do Norte (RN), tomando como referência de contexto o Fundef e o Fundeb. De cunho documental, a investigação utilizou os vencimentos dos professores, referenciados na Lei do Piso e informações localizadas nos respectivos planos de carreira. Embora de forma diferenciada, a Lei do Piso produziu efeitos positivos nos vencimentos de professores das redes públicas analisadas.
\end{abstract}

Palavras-chave: Lei do Piso. Vencimento dos professores. Professores de escola pública.

Abstract: This article intends to analyze the effects of the Base Salary Law on municipal teachers of Teresina (PI) and Natal (RN) payments, taking the Fundef and Fundeb contexts as a reference. As a documental research, the investigation approached teachers' salaries which were under the Base Salary Law and the information in its careers' plan. Although in a differentiated way, according to the researched network, the Base Salary Law provides positive effects on teachers' salaries of public networks analyzed.

Keywords: the base salary law; teacher salary; state school teachers.

Resumen: Este artículo analisa los efectos de la Ley de Piso enlossueldos de losprofesores de las redes públicas municipales de Teresina y de Natal y de las redes estatales de Piaui (PI) y de Río Grande del Norte (RN), tomando como referencia de contexto al Fundep y elFundeb. Como fuente documental, lainvestigación utilizól os sueldos de los profesores mencionados enla Ley de Piso e informaciones encontradas enlos respectivos planes de Carrera. Aunque de forma diferenciada, la Ley de Piso produjo efectos positivos enlos sueldos de los profesores de las redes públicas analizadas.

Palabras clave: Ley de Piso. Sueldo de los professores. Professores de lared pública. 


\section{INTRODUÇÃO}

O tema valorização do magistério tem sido objeto de discussão em inúmeros espaços acadêmicos. Geralmente, está relacionado às dimensões salariais, condições de trabalho e formação. Com a instituição da Lei n ${ }^{\circ}$ 11.738/2008 (BRASIL, 2008), conhecida como Lei do Piso, a dimensão salarial ganhou visibilidade. O motivo dessa visibilidade está relacionado à importância que o eixo valorização conquistou na legislação que norteia as políticas educacionais brasileiras, sobretudo nas últimas décadas.

Neste sentido, a Constituição Federal de 1988 foi o primeiro documento legal a estabelecer a necessidade de implementar ações, entre elas, Planos de Cargos, Carreira e Remuneração (PCCR) e regulamentar o Piso Salarial Profissional Nacional (PSPN), conforme art. 208, inciso V. No entanto, foi somente a partir dos anos 1990, que alterações na legislação estabeleceriam dispositivos para a sua efetivação. Assim, a legislação que instituiu o Fundo de Manutenção e Desenvolvimento do Ensino Fundamental e de Valorização do Magistério (Fundef), entre 1996 e 2006 e o Fundo de Manutenção e Desenvolvimento da Educação Básica e de Valorização dos Profissionais da Educação (Fundeb), a partir de 2007, determinou que Estados e Municípios aplicassem um percentual mínimo de 60\% da receita do Fundo na remuneração do magistério.

Convém destacar que, com a substituição do Fundef pelo Fundeb, a questão da valorização profissional continuou central. Dessa forma, a Lei $\mathrm{n}^{\mathrm{o}}$ 11.494/07, que regulamentou o Fundeb, passou a especificar as responsabilidades de Estados e municípios com a política de valorização dos profissionais da educação, encaminhando para a necessidade de planos de carreira e remuneração dos profissionais da educação básica da rede pública, visando assegurar a remuneração condigna desses profissionais, mediante a instituição de um Piso Salarial profissional. A definição do Piso constitui uma das principais lutas do movimento sindical dos professores e fator de maior resistência por parte de Estados e municípios.

A literatura tem apresentado indícios dos efeitos da política de Fundos na valorização do magistério. Por meio de relatórios do MEC sobre o Fundef (1996-2006), constatou-se a elevação da remuneração dos professores em regiões localizadas do Brasil, como o Nordeste, por exemplo. No entanto, na literatura da área, verificou-se, em alguns casos, que se passou a pagar apenas o salário mínimo em municípios que não cumpriam essa determinação constitucional (DAVIES, 1999; ARELARO, 2007), havendo, em outros casos, a constatação da elevação média real da remuneração dos professores no período (GOUVEIA, SOUZA, 
2011). Estudos de Gatti e Barreto (2009), Alves e Pinto (2011) apontam, também, que essa média tem permanecido inferior à de outros profissionais com o idêntico tempo de formação.

Com a instituição da Lei do Piso, em 2008, tem início a política de valorização do magistério, a qual merece estudo especial, com o intuito de avaliar os seus efeitos nos vencimentos e nas remunerações dos professores, destacando, neste artigo, a situação vivenciada por dois estados da região Nordeste. O artigo contextualiza os efeitos da Lei do PSPN ( ${ }^{\circ}$ 11.738/2008) nos vencimentos de professores das redes públicas municipais de ensino de Teresina e de Natal e das redes estaduais de ensino do Piauí (PI) e do Rio Grande do Norte (RN), tomando, como referência, as políticas do Fundef e Fundeb.

A Lei do Piso estabelece, no $₫ 1$ o do art. 2 o, que "o piso salarial profissional nacional é o valor abaixo do qual a União, os Estados, o Distrito Federal e os Municípios não poderão fixar o vencimento inicial das Carreiras do magistério público da educação básica, para a jornada de, no máximo, 40 (quarenta) horas semanais". Portanto, a referida lei utiliza, como referência, o professor no início da carreira, compreendendo esse, com nível médio, ou seja, o Curso Normal.

Este trabalho, portanto, constitui-se numa pesquisa de cunho documental, tendo, como base empírica de coleta, informações disponibilizadas em portais públicos, especificamente nas páginas das secretarias das quatro redes de ensino envolvidas, bem como nos portais do MEC e FNDE. Nas páginas das secretarias, foram obtidas tabelas de Vencimentos dos professores de cada uma das redes de ensino, considerando os professores efetivos (do quadro permanente), com carga horária de trabalho semanal 40 horas, posicionados no início do plano de carreia e com formação em nível de Ensino Médio (Curso Normal ou o Antigo Magistério), conforme perfil definido como referência na Lei do Piso. Ademais, foram utilizadas informações localizadas nos planos de carreira a que estão submetidos os professores das respectivas redes de ensino.

\section{PLANOS DE CARREIRA E A LEI DO PISO}

Os Planos de Cargo, Carreira e Remuneração, no âmbito do magistério, é reivindicação histórica dos professores, contemplando aspectos da valorização docente, tais como: a estrutura da carreira, a progressão horizontal e vertical e a evolução na remuneração dos professores, sendo o vencimento um item relevante no contracheque do professor.

Em função da importância dos Planos de Carreira, visando estabelecer um horizonte para a trajetória profissional do professor, a legislação educacional tem fixado prazos para que os Estados, o Distrito Federal e os Municípios 
implantem, no âmbito de suas redes de ensino, Planos de Carreira e Remuneração dos profissionais do Magistério (Lei n ${ }^{\circ}$ 9.424/1996) ou profissionais da Educação Básica (Lei no 11.494/2007). Com a edição da Lei do Piso, um novo prazo foi estabelecido:

Art. $6^{\circ}$ - A União, os Estados, o Distrito Federal e os Municípios deverão elaborar ou adequar seus Planos de Carreira e Remuneração do Magistério até 31 de dezembro de 2009 , tendo em vista o cumprimento do piso salarial profissional nacional para os profissionais do magistério público da Educação Básica, conforme disposto no parágrafo único do art. 206 da Constituição Federal (BRASIL, 2008).

É válido destacar que os professores das quatro redes de ensino estudadas neste trabalho, possuem Planos de Carreira e atendem a essa demanda, tanto em relação ao que estabelecia a Lei do Fundef quanto a Lei do Fundeb, bem como a Lei $n^{\circ}$ 11.738/2008 (Lei do Piso). Portanto, as referidas redes de ensino não precisariam preocupar-se em atender a tal demanda até de 31 de dezembro 2009, para elaborar planos de carreira, porque já os possuíam. Seria tão somente fazer pequenos ajustes nos Planos, sem alterar a estrutura da carreira.

Segundo Sales (2012), acredita-se que o clima gerado após a publicação das Diretrizes Nacionais para os Novos Planos de Carreira e de Remuneração para o Magistério Público dos Estados, do Distrito Federal e dos Municípios, pelo Conselho Nacional de Educação (CNE), conforme o Parecer CNE/ CEB n ${ }^{\circ}$ $9 / 2009$, tenha contribuído para se passar a ideia de que todos os entes federados teriam que elaborar ou adequar seus planos de carreira até 31/12/2009.

Supõe-se que os elaboradores da Lei $\mathrm{n}^{\circ} 11.738 / 2008$, bem como os conselheiros do Conselho Nacional de Educação (CNE), tinham consciência do impacto que causaria a Lei do Piso nos Planos de Carreira dos entes federados, em face da presença da palavra adequar/adequação existente tanto na Lei do Piso quanto nas referidas Diretrizes Nacionais do CNE.

Na prática, os entes federados tinham consciência de que haveria impacto, tanto é que alguns estados brasileiros (Rio Grande do Sul, Paraná, Santa Catarina, Mato Grosso do Sul e Ceará) consideraram a Lei do Piso inconstitucional, pois deram entrada no Supremo Tribunal Federal (STF) com uma Ação Direta de Inconstitucionalidade (ADIn). Até que o STF julgasse o mérito da referida ADIn, ocorrido em 06/04/2011, cada rede de ensino reagiu de forma diferenciada, conforme a situação em que se encontravam, em relação ao que vinham pagando aos seus professores. Enquanto umas procuravam atender imediatamente, à Lei do Piso, já em 2009, outras passaram atender somente em 2012, após a decisão do STF de negar o respectivo pedido dos cinco estados. 
Nesse contexto, abre-se um parêntese para que se esclareça como se chegou ao valor do Piso para 2009. Quando da publicação da Lei no 11.738/2008, o valor era de $\mathrm{R} \$ 950,00$, para uma jornada de 40 horas, para os professores no início da carreira, e deveria entrar em vigor em $1^{\circ}$ de janeiro de 2008 . Pelo $\$ 2^{\circ}$, do art. $3^{\circ}$, "até 31 de dezembro de 2009, admitir-se-á que o Piso salarial profissional nacional compreenda vantagens pecuniárias, pagas a qualquer título”. Portanto, a partir de 2010, o valor do Piso não deveria ser inferior ao vencimento; isso levou muitos estados e municípios a incorporar todos os abonos e vantagens salariais ao vencimento, a fim de acabar com uma prática muito comum, em todo o país, ou seja, congelando o vencimento e concedendo aumento por meio de abonos. O valor do Piso de $\mathrm{R} \$ 950,00$ deveria ser atualizado no ano seguinte, levando em consideração o crescimento do valor anual mínimo por aluno, referente aos anos iniciais do ensino fundamental urbano $[\ldots]$ :

Art. $5^{\circ}$. O piso [...] será atualizado, anualmente, no mês de janeiro, a partir do ano de 2009.

Parágrafo único. A atualização [...] será calculada utilizando-se o mesmo percentual de crescimento do valor anual mínimo por aluno referente aos anos iniciais do ensino fundamental urbano [...]. (BRASIL, 2008).

O Ministério da Educação (MEC), por meio de consulta à Advocacia Geral da União (AGU), fixou, em R \$ 1.024,67, o valor do Piso salarial profissional nacional para o ano de $2010^{1}$. Nesse caso, não foi considerado o aumento referente ao ano de 2009, visto que o valor de $\mathrm{R} \$ 950,00$ deveria vigorar a partir de janeiro de 2008. Dessa forma, a lei foi descumprida.

Nos anos sequentes, o PSPN foi reajustado, considerando a variação dos dois últimos anos do valor mínimo nacional por aluno/ano, como regra de reajuste. A tabela 1 traz os valores nominais do PSPN e os percentuais de reajustes, definidos pelo Ministério da Educação (MEC), para o período de 2009 a 2015.

1 Para chegar a este percentual, a AGU tomou por base a diferença entre o valor efetivo do Fundeb por aluno praticado em $2008(\mathrm{R} \$ 1.132,34)$ e o de 2009 ( $\mathrm{R} \$ 1.221,34)$. A diferença apurada foi de 7,86\%. Com isso, o Piso da jornada de 40 horas passou dos $\mathrm{R} \$ 950$ para $\mathrm{R} \$ 1.024,67$ em janeiro de 2010. Dessa forma, o governo não considerou o aumento do ano de 2009, o qual elevaria o valor determinado pela AGU (R\$ $1.024,67)$. 


\section{Tabela 1 - Valores nominais do PSPN e os percentuais de reajustes definidos pelo MEC no período de 2009 a 2015.}

\begin{tabular}{|c|c|c|}
\hline Período & Valor Nominal & Reajustes \\
\hline 2009 & 950,00 & - \\
\hline 2010 & $1.024,67$ & 7,86 \\
\hline 2011 & $1.187,09$ & 15,85 \\
\hline 2012 & $1.451,75$ & 22,22 \\
\hline 2013 & $1.567,00$ & 7,97 \\
\hline 2014 & $1.697,00$ & 8,32 \\
\hline 2015 & $1.917,78$ & 13,01 \\
\hline
\end{tabular}

Fonte: Portarias Interministeriais do MEC (2009-2015)

Na tabela, constam os valores do Piso Salarial Profissional Nacional (PSPN), definidos pelo MEC, a serem pagos, em cada ano, por estados e municípios, aos professores com nível médio na modalidade normal (magistério), considerando uma jornada de 40 horas semanais. No tocante aos dados, percebese que o PSPN, no período (2009 a 2015), revelou um crescimento de 101,9\%, estabelecendo uma média de 13,11\% ao ano. Vale destacar que os anos com maiores reajustes foram 2011, 2012 e 2015, entretanto, o ano que representou maior percentual foi 2012. Esses percentuais foram registrados no período do último mandato do presidente Lula e no posterior, governo de Dilma, contribuindo para implementar uma política de valorização salarial do magistério, pela aplicação dos percentuais ao PSPN, especificamente sobre o vencimento básico dos professores. Portanto, pode-se inferir que o PSPN vem apresentando substancial crescimento, uma vez que esse percentual de crescimento, no período de 2009 a 2015, foi superior ao do salário mínimo nacional.

Por outro lado, embora Pinto (2009) aponte que o PSPN vem, gradativamente, apresentando avanços práticos, observa-se que muitos estados e municípios não o cumprem, seja no valor a ser pago, seja na implementação de um terço da carga horária destinada às atividades de planejamento. Ademais, o poder público não reestrutura a questão dos mecanismos punitivos ou implementação de acordos financeiros capazes de garantir o pagamento determinado legalmente. Portanto, a falta de instrumentos legais coercitivos tem contribuído para que estados e municípios busquem estratégias diferenciadas, com o intuito de se adaptar com base na nova realidade desenhada pela Lei do Piso.

Neste sentido, a partir da repercussão do valor do Piso Nacional de 2010 $(\mathrm{R} \$ 1.024,67)$ na estrutura salarial dos Planos de Carreira vigentes, àquela época, em Estados e Municípios, elevando significativamente a folha de pagamento, 
foi possível compreender os motivos que levaram os elaboradores da Lei $n^{\circ}$ 11.738/2008, bem como os conselheiros do CNE, a colocarem a palavra adequar/ adequação, tanto na Lei do Piso quanto nas referidas Diretrizes Nacionais.

Nesse contexto, Estados e Municípios tiveram que se ajustar à nova realidade, em função do impacto financeiro na folha de pagamento, considerando que a lei do Piso determina que o seu valor tome como referência, o vencimento e não a remuneração. Considerando que muitas gratificações estavam vinculadas ao vencimento (em geral os vencimentos eram baixos em relação à remuneração), o impacto na folha de pagamento seria significativo caso nenhum ajuste fosse realizado no plano de carreira ou na forma como vinha sendo pago aos professores.

A definição dos conceitos de vencimento e remuneração se faz necessária, haja vista que muitos gestores, segundo Sales, Cruz e Silva (2014), optaram por basear sua política salarial na inclusão de abonos, gratificações, dentre outros itens que compõem a chamada parte variável do salário. O vencimento representa a parte fixa do montante recebido pelo docente ao final do mês, sem qualquer tipo de acréscimo. Portanto, a política de reajuste salarial incide diretamente sobre esse elemento no contracheque. No caso da remuneração, ela representa o montante recebido, incluindo o vencimento e outros componentes recebidos pelo trabalhador, por exemplo, as gratificações, os abonos, entre outros.

Considerando ainda que o impacto da Lei do Piso poderia variar conforme a realidade daquilo que estava sendo praticado, naquela época, por cada Estado e Municípios, neste trabalho, são analisados os vencimentos pagos aos professores correspondentes à série histórica 2006 a 2014, com magistério (nível médio) e 40h no início da Carreira. Vale destacar que 2006, corresponde ao último ano do Fundef e 2014 o fim da coleta de dados da Pesquisa "Remuneração dos professores da educação básica: Fundeb e PSPN”, o qual este estudo está inserido.

\section{VENCIMENTOS DOS PROFESSORES: EFEITOS DA LEI DO PISO EM 2006 A 2014}

Nas tabelas 2 e 3, constam, além da variável vencimento, as variáveis Valor Fundo e Valor Piso. A tabela 2 apresenta essas duas variáveis em valores nominais enquanto a tabela 3 , as mesmas variáveis em percentuais. A variável Valor Fundo corresponde ao valor mínimo nacional por aluno/ano (VMNAA), definido pelo Governo Federal, em cada ano da série histórica analisada. A variável Valor Piso corresponde aos valores do Piso Salarial Profissional Nacional 
para os profissionais do magistério público da educação básica, correspondentes às redes municipais de Teresina e de Natal e das redes estaduais do Piaú (PI) e do Rio Grande do Norte ( $\mathrm{RN})$.

Nas duas tabelas, foram considerados os vencimentos do professor com jornada de 40 horas e formação em nível médio, magistério, posicionado no início do seu Plano de carreira, na série histórica 2006 a 2014. Portanto, as tabelas 2 e 3 apresentam o ponto de partida das análises relacionadas aos efeitos da Lei do Piso nos vencimentos dos professores das quatro redes públicas.

Tabela 2 - Série histórica (2006 a 2014) dos vencimentos dos professores com magistério (nível médio, 40 horas e início da carreira) das redes públicas do Piauí e do Rio Grande do Norte (estadual e capital), comparados aos valores do Piso e valores mínimos pagos por alunos (Fundef/Fundeb) em valores nominais.

\begin{tabular}{|c|c|c|c|c|c|c|}
\hline Ano & Teresina & Natal & PI & RN & $\begin{array}{c}\text { Valor } \\
\text { Fundo }\end{array}$ & $\begin{array}{c}\text { Valor } \\
\text { Piso }\end{array}$ \\
\hline 2006 & 369,94 & $1.010,88$ & 700,00 & 826,67 & 706,49 & \\
\hline 2007 & 381,04 & $1.250,86$ & 780,00 & 826,67 & 946,29 & \\
\hline 2008 & 397,66 & $1.318,78$ & 840,00 & 826,67 & $1.132,34$ & 950,00 \\
\hline 2009 & 417,54 & $1.477,03$ & 930,00 & 950,08 & $1.221,34$ & 950,00 \\
\hline 2010 & $1.024,70$ & $1.620,68$ & $1.024,68$ & 950,08 & $1.414,85$ & $1.024,67$ \\
\hline 2011 & $1.167,70$ & $1.800,08$ & $1.187,08$ & 885,77 & $1.729,28$ & $1.187,08$ \\
\hline 2012 & $1.451,00$ & $1.800,08$ & $1.681,00$ & $1.451,36$ & $1.867,15$ & $1.450,79$ \\
\hline 2013 & $1.566,66$ & $1.980,08$ & $1.681,00$ & $1.567,03$ & $2.022,51$ & $1.566,64$ \\
\hline 2014 & $1.697,00$ & $2.384,28$ & $1.814,98$ & $1.697,40$ & $2.285,57$ & $1.697,39$ \\
\hline
\end{tabular}

Fonte: Elaborada pelos autores, a partir das Tabelas de vencimentos das quatro redes de ensino analisadas, dos valores do PSPN e do VMNAA (valor mínimo nacional por aluno ano). 
Tabela 3 - Série histórica (2006 a 2014) dos percentuais acumulados dos vencimentos dos professores com magistério (nível médio, 40 horas e início da carreira) das redes públicas do Piauí e do Rio Grande do Norte (estadual e capital) comparados aos valores do Piso e valores mínimos pagos por alunos (Fundef/Fundeb).

\begin{tabular}{|c|c|c|c|c|c|c|}
\hline Ano & Teresina & Natal & PI & RN & $\begin{array}{c}\text { Valor } \\
\text { Fundo }\end{array}$ & $\begin{array}{c}\text { Valor } \\
\text { Piso }\end{array}$ \\
\hline 2006 & & & & & & \\
\hline 2007 & 3,0 & 23,7 & 11,4 & 0,0 & 33,9 & \\
\hline 2008 & 7,5 & 30,5 & 20,0 & 0,0 & 60,3 & \\
\hline 2009 & 12,9 & 46,1 & 32,9 & 14,9 & 72,9 & 0,0 \\
\hline 2010 & 177,0 & 60,3 & 46,4 & 14,9 & 100,3 & 7,9 \\
\hline 2011 & 215,6 & 78,1 & 69,6 & 7,2 & 144,8 & 25,0 \\
\hline 2012 & 292,2 & 78,1 & 140,1 & 75,6 & 164,3 & 52,7 \\
\hline 2013 & 323,5 & 95,9 & 140,1 & 89,6 & 186,3 & 64,9 \\
\hline 2014 & 358,7 & 135,9 & 159,3 & 105,3 & 223,5 & 78,7 \\
\hline
\end{tabular}

Fonte: Elaborada pelos autores, a partir das Tabelas de vencimentos das quatro redes de ensino analisadas e dos valores do PSPN e do VMNAA (valor mínimo nacional por aluno ano).

Analisando a tabela 2, verifica-se que os professores da rede pública municipal de ensino de Natal (detentores da carreira subsidiada pela Lei $\mathrm{n}$. 058/2004), durante toda a série histórica, receberam vencimentos acima do que estabelecia a Lei do Piso. Das quatro redes em análise, foi a única que, em 2008, não precisou recorrer a nenhuma estratégia para atender a Lei do Piso, pois já pagava vencimentos acima de $\mathrm{R} \$ 950,00$. Por outro lado, das quatro redes analisadas, a que estava com os vencimentos dos professores, bem distante do que estabelecia a lei do Piso, para 2008 e 2009, era a rede pública municipal de ensino de Teresina, visto que pagava nos citados anos, apenas 397,66 e 417,56, respectivamente, enquanto o valor do Piso era de $\mathrm{R} \$ 950,00$. No entanto, no período da série (2006 a 2014), foi a rede que revelou o maior crescimento nos vencimentos dos professores no início da carreira com nível médio (145,4\%), sendo a rede que fez o maior esforço para elevar o vencimento, de um patamar baixo, para igualar ao valor do Piso Nacional. De outro modo, a rede estadual do Piauí também não pagava o valor do Piso em 2008 e 2009, todavia os valores eram mais próximos de $\mathrm{R} \$ 950,00$. Segundo Soares (2016), a Rede Estadual do Piauí, ao iniciar a incorporação de algumas gratificações ao vencimento, ainda em 2006, preparava-se para a implementação da Lei do Piso. 
A rede estadual do Rio Grande do Norte (possui a carreira subsidiada pela Lei Complementar n. 322/2006), apesar de pagar o valor fixado pela Lei do Piso em 2009, nos anos seguintes, não o faz e, somente a partir de 2012, os valores pagos superam em alguns centavos os valores estabelecidos pela Lei do Piso. Portanto, a partir de 2012, a rede estadual do Rio Grande do Norte passa atender à lei do Piso, quando não havia mais como adiar esse atendimento, uma vez que o Supremo Tribunal Federal, em 06/04/2011, julgou e negou a Ação Direta de Inconstitucionalidade (ADIn), de 29/10/2008.

Cada uma das quatro redes de ensino apresenta comportamentos diferenciados em relação à sua convivência com a lei do Piso. Tal comportamento foi motivado pela preocupação com o valor do vencimento que era pago quando do anúncio da lei do Piso, visto que a lei toma, como referência, para o valor do piso, o vencimento e não a remuneração. Vale destacar que as redes de ensino, em geral, atenderiam à lei, caso fosse considerado o valor da remuneração, porém nem todas atendiam quando se considera o valor do vencimento. Neste sentido, a tendência esperada era a elevação do vencimento e, consequentemente, sua aproximação com a remuneração. Portanto, os efeitos da implantação da Lei do Piso foram percebidos nos vencimentos dos professores e no movimento de incorporação de gratificações ao vencimento, como estratégia para aproximar o vencimento da remuneração.

Ademais, aquelas redes com vencimentos baixos em relação à remuneração, tiveram que, rapidamente, se ajustar à Lei do Piso. Foi o caso da rede de Teresina, que já, em 2009, teve sua Lei Complementar nº 3.951, de 17 dezembro de 2009. Seus efeitos, portanto, foram sentidos no ano seguinte (2010), quando os professores, no início da carreira e com nível médio, tiveram um expressivo aumento nos seus vencimentos $(145,4 \%)$. No entanto, passaram a receber, apenas, um pouco acima (na ordem de centavos) do valor da lei do Piso.

Concernente aos efeitos do impacto do Fundeb e do PSPN na remuneração dos professores dos referidos estados, pode-se concluir que a variável Valor Fundo (Fundef/Fundeb) teve crescimento nas receitas da educação, sendo percebido por meio da elevação do valor mínimo nacional por aluno/ ano Fundef/Fundeb, uma vez que cresceu nominalmente 223,5\%, percentual bem acima do percentual acumulado pelo Salário Mínimo (106,9\%) no mesmo período. Portanto, com o crescimento do valor mínimo nacional por aluno/ ano acima da inflação, indiretamente, o PSPN também cresceu, uma vez que sua atualização anual acompanha a variação do valor-aluno Fundef/Fundeb (valor mínimo nacional por aluno/ano), cuja variação considera os dois últimos anos, conforme estabelece o Parágrafo Único do Art. $5^{\circ}$ da Lei do Piso 
Vale destacar que, embora o PSPN tenha, indiretamente, impactado a remuneração dos professores, sua implantação sofreu impacto direto e expressivo no valor do vencimento, uma vez que contribuiu decisivamente para aproximar os valores do vencimento e da remuneração. No caso da rede pública estadual de ensino do Piauí, a partir de 2012, segundo Fontineles (2017), essa aproximação atinge o seu limite máximo, ou seja, o vencimento se iguala à remuneração, motivada pela Lei Estadual n ${ }^{\circ}$. 6.215/2012, que encorpou ao contracheque dos professores a última gratificação existente, denominada Gratificação de Regência. Na rede pública municipal de ensino de Teresina, a aproximação também aconteceu, só que em menor proporção, pois a relação entre o vencimento e a remuneração saiu de 46,7\%, em 2006, para 71,6\% em 2012.

Convém assinalar que as grandes mudanças ocorridas nos Planos de Carreiras das redes analisadas, aconteceram em função da necessidade de se ajustar esses planos à nova realidade trazida pela Lei do Piso (Lei no 11.738, de 16 de julho de 2008), especialmente após 27 de abril de 2011, com a queda da ADIn. Destaca-se, ainda, que, na rede de Teresina, os efeitos da Lei do Piso no Plano de Carreira dos professores foram sentidos a partir de 2010, com a implementação da Lei Complementar nº 3.951, de 17.12.2009. Na rede estadual de Piauí, os efeitos da lei do Piso na carreira dos professores foram percebidos, de forma expressiva, a partir de 2012, quando foi incorporada a última Gratificação de Regência, por meio da Lei Estadual nº. 6.215/2012.

$\mathrm{Na}$ rede pública municipal de ensino de Natal, os reajustes ocorreram anualmente, com exceção de 2006 e 2012, embora, em 2006, tenha sido publicada a Lei n ${ }^{\circ} 5.726 / 06$, determinando a antecipação do Piso salarial, denominado de pró-piso nacional nos vencimentos e proventos aos professores ativos e inativos do quadro do magistério público municipal. De modo geral, entende-se que houve uma política de valorização do vencimento, razoavelmente satisfatória, seja no início ou no final da carreira, comprovando ganhos. Entretanto, segundo Araújo (2017), evidencia-se que a melhoria salarial, mesmo com a política de Fundos (Fundef e Fundeb), o Plano de Cargo, Carreira e Remuneração (PCCR) dos professores da Rede Pública Municipal de Ensino de Natal de 2004 e do PSPN, ainda não efetivou a condigna valorização salarial, apresentando melhorias, com lacunas no cumprimento das definições legais e dos anseios da categoria, como o caso da promoção (mudança de nível conforme formação) e da progressão (mudança de classe promovida pelo tempo de serviço e pela avaliação de desempenho).

Em relação à rede pública estadual de ensino do Rio Grande do Norte, as diferenças entre os vencimentos dos professores estão diretamente relacionadas à implementação do PSPN, uma vez que se entende que o professor com formação 
em curso superior ou pós-graduação, segundo Araújo (2017), deve apresentar vencimentos superiores àqueles determinados na Lei do Piso. Isso ocorre porque o valor do PSPN refere-se ao vencimento mínimo que ele deve receber no início de sua carreira com formação de nível médio.

Em relação aos aspectos positivos do PSPN, Carvalho (2013, p. 8) afirma que a Lei do Piso "estimularia a realização de concursos públicos, a busca por qualificação e titulação pelos professores, a elaboração de planos de carreira, a dedicação exclusiva do professor a um único estabelecimento de ensino público e melhor remuneração". Corroborando o entendimento desse autor, Sonobe e Pinto (2015, p.14) ressaltam que, a partir do estabelecimento do PSPN, "espera-se diminuir a discrepância existente entre diferentes regiões do país, buscando elevar o patamar da qualidade de ensino brasileiro". Logo, observa-se que as expectativas em torno das conquistas para a categoria, através do PSPN, são positivas, em sua maioria. No entanto, a história das políticas educacionais brasileiras permite afirmar que não bastam legislações bem desenhadas, visto que, na implementação dessas leis, é necessário, também, que haja luta e mobilização social para garantir as conquistas desejadas.

\section{CONSIDERAÇÕES FINAIS}

Ao analisar os efeitos da Lei do Piso n ${ }^{\circ} 11.738 / 2008$, nos vencimentos de professores das redes públicas municipais de Teresina e de Natal bem como das redes estaduais do Piauí (PI) e do Rio Grande do Norte (RN), tomou-se, como referência, a política de Fundos (Fundef e Fundeb).

É importante destacar que os referidos Fundos trouxeram conquistas importantes, tais como: a vinculação de recursos para a remuneração dos professores (Fundef) ou profissionais da educação (Fundeb); a determinação para a elaboração ou reformulação de Planos de Carreira; as diretrizes para a carreira do magistério (Resolução n ${ }^{\circ}$ 03/1997 e a Resolução no 02/2009 do CNE); a aprovação da Lei n ${ }^{\circ} 11.738$ do PSPN, que define o vencimento base, ou seja, o mínimo a ser pago ao professor com magistério, para 40 horas semanais, com um $1 / 3$ de hora atividade para planejamento. Esses elementos configuram importantes conquistas da política de Fundos e da luta sindical.

É importante ainda salientar que a Lei do Piso foi instituída visando beneficiar os professores da educação básica que atuam nas redes públicas de ensino. No contexto de sua implantação, na maioria dos estados, a remuneração dos professores era composta por gratificações e abonos, além do vencimento. Em muitos casos, o vencimento era tão irrisório que chegava a corresponder menos da metade da remuneração. Com a lei do Piso em vigor, alguns municípios 
até que pagavam o Valor Piso, caso fosse considerada a remuneração, no entanto, considerando o vencimento que era pago, ficava distante de atender àquele valor. A alternativa encontrada por muitos gestores foi incorporar as gratificações aos vencimentos, visando atender à lei do Piso.

Neste sentido, não se pode falar dos efeitos do PSPN na remuneração dos professores de escolas públicas de educação básica (do Piauí e do Rio Grande do Norte) sem fazer referência aos efeitos do Fundef e do Fundeb, uma vez que os percentuais de aumentos anuais concedidos dados ao PSPN tomam tem como referencial, o valor mínimo nacional por aluno, fixados pelo Governo Federal nos dois últimos anos antes de reajuste. No período analisado, em termos nominais, enquanto o salário mínimo cresceu $106,9 \%$, a variação do valor mínimo nacional por aluno cresceu $223,5 \%$, superando em mais de $50 \%$ o crescimento do salário mínimo, o que expressa o impacto positivo do Fundeb no crescimento do PSPN. Em face do exposto, é pertinente a seguinte questão: Considerando a política de Fundos e a lei do Piso, qual política teve mais impacto nos vencimentos dos professores?

É válido assinalar que a política de Fundos, por ser vinculada ao montante de impostos arrecadados, foi importante para aumentar os recursos da educação, especialmente nos estados que recebem complementação da União. Embora o crescimento do valor mínimo nacional por aluno esteja relacionado ao crescimento dos impostos, o crescimento do PSPN está vinculado ao crescimento dos recursos do Fundeb. Em um primeiro momento, pode-se inferir que a política de Fundos teve impacto positivo nos vencimentos dos professores, no entanto a lei do Piso, ao vincular os reajustes do PSPN à variação do valor mínimo nacional por aluno, produziu também impacto positivo nos vencimentos dos professores. Portanto, o mérito da Lei do Piso foi vincular os reajustes do PSPN ao Fundeb, sendo que este último, isolado, não seria capaz de elevar os referidos vencimentos, pelo fato de não haver artigos, em sua legislação, que regulamente os reajustes dos vencimentos ou a remuneração dos professores. Em relação ao Fundef, os seus efeitos, na remuneração média dos professores, segundo Davies (1999) e Arelaro (2007), só foram percebidos, nos primeiros anos de sua implantação, em função do pagamento do salário mínimo em municípios que não cumpriam essa determinação constitucional.

Conclui-se, finalmente, que a política de Fundos (Fundef/Fundeb), conforme consta na legislação, não produziu efeito determinante para elevar os vencimentos e as remunerações dos professores da educação básica que atuam em escolas públicas brasileiras, especificamente, nas redes públicas analisadas, uma vez que tem funcionado, desde a implantação da Lei do Piso, como indicador de reajuste, por meio da variação do valor mínimo nacional 
por aluno. Portanto, embora a elevação dos vencimentos dos professores esteja relacionada, simultaneamente, ao Fundeb e à Lei do Piso, foi esta última que agiu, de forma determinante, para que estados e municípios elevassem os vencimentos dos professores. Neste sentido, a Lei do Piso $n^{0} 11.738 / 2008$, embora, não obstante diferenciada, produziu, conforme a rede analisada, efeitos positivos nos vencimentos de professores das redes públicas municipais de Teresina e de Natal e das redes estaduais do Piauí (PI) e do Rio Grande do Norte (RN).

\section{REFERÊNCIAS}

ALVES T., PINTO, J. M. de R. Remuneração e características do trabalho docente no Brasil: um aporte. 2011. Cadernos de Pesquisa, v. 41, n. 143, mai/ago, 2011. ARELARO, L. R. G. Fundef: uma avaliação preliminar dos dez anos de sua implantação. In: Anais da 30ª Reunião Anual da ANPED, 2007.

ARAÚJO. Fádyla Késsia Rocha de. Desafios da valorização dos professores Norte: carreira e remuneração (2009-2015). 37:331.2 f. 258. Tese (Doutorado em Educação) - Universidade Federal do Rio Grande do Norte, Programa de Pósgraduação em Educação, Natal, 2017.

ARELARO, Lisete Regina Gomes. Formulação e implementação das políticas públicas em educação e as parcerias público-privadas: impasse democrático ou mistificação política? Educação e Sociedade. Campinas, v.28, n. 100, 2007.

BRASIL. Constituição (1988). Constituição da República Federativa do Brasil. Edição administrativa do texto constitucional promulgado em 05 de outubro de 1988, com alterações adotadas pelas Emendas Constitucionais n¹/1992 a 56/2007 e pelas emendas Constitucionais de Revisão n. 1 a6/1994. Brasília: Senado Federal, 2008.

Lei $\mathbf{n}^{\circ} \mathbf{. 1 1 7 3 8}$, de 16 de julho de 2008b. Regulamenta a alínea "e" do inciso III do caput do art. 60 do Ato das Disposições Constitucionais Transitórias, para instituir o piso salarial profissional nacional para os profissionais do magistério público da educação básica. Disponível em: <http://www.planalto.gov.br/ ccivil_03/_Ato2007-2010/2008/Lei/L11738.htm>. Acesso em: 12 out. 2008. 
Lei $\mathbf{n}^{\mathbf{0}}$. 9.424, de 24 de dezembro de 1996f. Dispõe sobre o Fundo de Manutenção e Desenvolvimento do Ensino Fundamental e de Valorização do Magistério, na forma prevista no art.60, \ $7^{\circ}$, do Ato das Disposições Constitucionais Transitórias, e dá outras providências. Disponível: <https:// www.presidencia.gov.br/casacivil/site/static/le.htm> Acesso em: nov. 2005.

Lei $\mathbf{n}^{\mathbf{0}} \mathbf{. 1 1 . 4 9 4}$, de 20 de junho de 2007. Dispõe sobre o Fundo de Manutenção e Desenvolvimento da Educação Básica e de Valorização dos Profissionais da Educação - FUNDEB. Disponível em <www.planalto.gov.br/ ccivil>. Acesso em 10/jul./2008.

Lei $\mathbf{n}^{\circ}$ 6.215, de 01 de junho de 2012. Dispõe sobre o reajuste do vencimento dos profissionais do magistério público da educação básica, para atender ao piso nacional. Disponível em:http://www.seadprev2.pi.gov.br/ download/201208/SEAD08_e30e731909.pdf. Acesso em: 28 jan. 2018.

CARVALHO, Fabrício Aarão Freire. Política de valorização do magistério da educação básica no contexto recente da política de fundos: análise da carreira docente em Ananindeu, PA. In: Simpósio brasileiro de política e administração da educação, 26., 2013. Anais... 2013. Disponível em: http://www.anpae.org. br/simposio26/1 comunicacoes/FabricioCarvalho-ComunicacaoOral-int.pdf $>$. Acesso em: 20 set. 2016.

DAVIES, Nicholas. O Fundef e o orçamento da educação - desvendando a caixa preta. Campinas, SP: Autores Associados, 1999.

FONTINELES, I. C. da S. Artífices de seu Ofício: a relação entre a formação e a remuneração dos professores das redes públicas piauienses (1996-2016). 179 f. Dissertação (Mestrado em Educação) - Programa de Pós-Graduação em Educação da Universidade Federal do Piauí. Teresina, 2017.

GATTI, B. A.; BARRETO, E. S. de SÁ. Professores do Brasil: impasses e desafios. Brasília, UNESCO, 2009.

GOUVEIA, A. B, SOUZA, A. R. Os trabalhadores docentes da educação básica em uma leitura possível das políticas educacionais. Arquivos Analíticos de Políticas Educativas, vol. 19, jan, 2011. 
NATAL. Secretaria Municipal de Educação. Lei Complementar $\mathbf{n}^{\mathbf{0}}$ 58, de 13 de setembro de 2004: Plano de Cargos, Carreira e Remuneração e Estatuto do Magistério Público Municipal de Natal. Natal, RN, 2004.

NATAL (Município). Lei $\mathrm{n}^{\circ}$ 5.726, de 10 de maio de 2006. Dispõe sobre a antecipação de valores pró-piso salarial nacional nos vencimentos e proventos dos professores ativos e inativos do quadro do magistério público municipal e determina outras providências. In Diário Oficial do Município. 2006.

PIAUÍ. Lei $\mathrm{n}^{\mathbf{o}}$. 4.212, de 5 de julho de 1988. Dispõe sobre o estatuto do magistério público de $1^{\circ}$ e $2^{\circ}$ graus do Estado do Piauí e dá outras providências. Teresina, 1988. Disponível em: $<$ http://legislacao.pi.gov.br/ legislacao/default/ato/12635 >. Acesso em: 20 nov. 2015.

PINTO, José Marcelino de Rezende. Remuneração adequada do professor: desafio à educação brasileira. Revista Retratos da Escola, Brasília, v. 3, n. 4, p. 51-67, jan. /jun. 2009. Disponível em: <http//www.esforce.org.br>

RIO GRANDE DO NORTE. Lei Complementar n. 322/06, que dispõe sobre o Estatuto e o Plano de Cargos, Carreira e Remuneração do Magistério Público Estadual, referente à educação básica e à educação profissional. Disponível em <www.governorn.gov.br/ccivil>.

SALES, Luís Carlos. Piso salarial nacional no plano de carreira do magistério público do município de Teresina. Educação em Foco, Belo Horizonte, ano 15, n. 19, p. 301-330, jun. 2012.

SALES, Carlos Sales; CRUZ, Rosana Evangelista da; SILVA Magna Jovita. Remuneração dos docentes da rede estadual de educação do Piauí. Fineduca. Porto Alegre, v.4, n.4, 2014. Disponível em: Acesso em 24 out. 2016.

SILVA, M. J. G. S. Custo Direto de Financiamento das Escolas Públicas Municipais de Teresina- Piaui. Dissertação (Mestrado em Educação) Programa de Pós-Graduação em Educação daUniversidade Federal do Piauí. Teresina, 2008. 
SILVA, S. O. O impacto do Fundef/Fundeb na Remuneração dos Profissionais do Magistério da Rede Estadual do Piaui. 2011. 108 f. Dissertação (Mestrado em Educação) - Programa de Pós-Graduação em Educação da UFPI, Universidade Federal do Piauí, Teresina, 2011.

SOARES, Marina Gleika Felipe. Remuneração e Carreira dos Profissionais da Educação Básica: o impacto da Lei do Piso na Rede Estadual do Piauí no período de 2008 a 2014. 85 f. Dissertação (Mestrado em Educação) - Programa de Pós-Graduação em Educação da Universidade Federal do Piauí. Teresina, 2016.

SONOBE, Aline Kazuko; PINTO, Marcelino de Rezende. Um olhar sobre a evolução da legislação acerca da valorização docente no Brasil. Fineduca Revista de Financiamento da Educação, Porto Alegre, v. 5, n. 5, 2015. Disponível em: <http://seer.ufrgs.br/fineduca>. Acesso em: 19 set. 2016.

TERESINA. Lei $\mathbf{n}^{\mathbf{0}} \mathbf{1 . 8 7 0}$, de 02 de dezembro de 1986. Dispõe sobre o Estatuto do Magistério Público de $1^{\circ}$ e $2^{\circ}$ Graus da Rede de Ensino do Município de Teresina. Diário Oficial do Município, Teresina, 05 dez. 1986.

. Lei $\mathbf{n}^{\mathbf{0}}$ 2.972, de 17 de janeiro de 2001. Dispõe sobre o Estatuto e o Plano de Cargos e Salários do Magistério Público da Rede de Ensino do Município de Teresina. Disponível em <http://www.semec.pi.gov.br/Dimon/Arquivos/Leg Leis/ Arquivo15.pdf>. Acesso em: 22 set. 2010.

. Decreto $\mathbf{n}^{\mathbf{0}} \mathbf{6 . 8 3 5}$, de 06 de julho de 2006. Regulamenta o art. 19, da Lei $\mathrm{n}^{\circ}$ 2.972, de 17 de janeiro de 2001, que dispõe sobre o Estatuto e o Plano de Cargos e Salários do Magistério Público da Rede de Ensino do Município de Teresina, alterado pela Lei $\mathrm{n}^{\circ} 3.515$, de 19 de maio de 2006. Diário Oficial do Município, Teresina, n. 1.109, 14 jul. 2006, p. 03 e 04. Disponível em <http:// www.teresina.pi.gov.br/dom/doc_diario/DOM1109-1-14072006.pdf>. Acesso em: 22 set. 2010.

Lei Complementar n. 3.951, de 17 de dezembro de 2009. Altera dispositivos da Lei $\mathrm{n}^{\circ}$ 2.972, de 17 de janeiro de 2001, que dispõe sobre o Estatuto e o Plano de Cargos e Salários do Magistério Público da Rede Ensino do Município de Teresina, e dá outras providências. Disponível em: $<$ http://www. semec.pi.gov.br/ Dimon/Arquivos/LegLeis/semec_3e5d36ddb3.pdf>. Acesso em: 20 dez. 2010. 
LUIS CARLOS SALES Possui graduação em Engenharia Civil pela Universidade Federal do Piauí (1981), mestrado em Educação pela Universidade Federal do Piauí (1995) e doutorado em Educação pela Universidade Federal do Rio Grande do Norte (1999). Atualmente é professor Titular da Universidade Federal do Piauí, do Programa de Pós-Graduação em Educação e do Departamento de Fundamentos da Educação. É Diretor do Centro de Ciências da Educação. Tem experiência na área de Educação, atuando principalmente nos seguintes temas: educação, representações sociais, financiamento da educação e política educacional. E-mail: lwis@ufpi.br

MAGNA FRANÇA possui Graduação em Pedagogia pela Universidade do Distrito Federal (1973), mestrado (1998) e doutorado (2001) em Educação pela Universidade Federal do Rio Grande do Norte. Atualmente exerce o cargo de professora titular do Centro e Programa de Pós-graduação em Educação da Universidade Federal do Rio Grande do Norte. Lider do grupo de Pesquisa Políticas e Gestão da Educação do DFPE/CE/UFRN. Coordena pesquisa em rede (12 IFES) sob a coordenação geral da U.F. do Paraná denominada Remuneração dos professores da educação básica: o Fundeb e o PSPN. E-mail: magna@ufrnet.br 